\title{
Some Notes on Publications of Professor Arnold Sorsby and on Alland Eye Disease (Forsius-Eriksson syndrome)
}

\section{P. J. WAARDENBURG*}

I made the acquaintance of Arnold Sorsby in 1930 at a small conference of the International Federation of Eugenic Organizations (I.F.E.O.) in London and Farnham (Dorset). I was already nearing middle-age, and he was younger. The President, Leonard Darwin, entertained us at a luncheon in London. This was also attended by the young Danish pathologist and geneticist Tage Kemp, the Dutch neuropsychiatrist G. P. Frets, who in 1924 proved that Mendel's laws were also valid for the head form (cephalic index), the lecturer in cytology in Utrecht Marianne van Herwerden, and the Germans E. Rüdin of Münich and A. Ploetz, the latter being the founder of the Archiv für Gessellschaftsbiologie und Rassenhygiene. The retirement of Professor Sorsby from the editorship of the fournal of Medical Genetics at the end of 1969 is an opportunity to mention with admiration the original and independent way in which he performed his scientific duties after his appointment as Research Professor of Ophthalmology at the London University at a rather young age. He had no predecessors. He had to take his own initiative and write, between 1931 and 1940, several publications without help of others, to which may be added his valuable book Genetics in Ophthalmology in 1951. His work culminated in his attempt to classify the choroidal and retinal dystrophies. In the meantime, he decided to publish books of wider scope. He had the gift of choosing a great number of the right scientific collaborators, and this accounts for the success of the three volumes of Modern Trends in Ophthalmology, published respectively in 1940, 1948, and 1955, which contained the most diverse and interesting subjects. In these volumes he wrote thirteen personal contributions. In 1953 Clinical Genetics appeared, a book dealing with the rapid progress of Medical Genetics, and not only with curiosities, but with the elucidation of the common problems of health and disease (see its preface).

* Address: Oosterbeek, De Valkenburcht 21, Holland.
We were glad in the Netherlands that Galton's term (1883) of Eugenics was replaced by Human Genetics, a neutral expression which is better suited to a science than is a more subjective term. Furthermore, everywhere, except in the Swiss Archiv der Fulius Klaus-Stiftung für Vererbungsforschung, Sozialanthropologie und Rassenhygiene, the very real danger of the German term Rassenhygiene was avoided, because it could be misused, as in Hitler's time, for anti-semitism, and nowadays in South Africa for separatism.

It is my intention, in this paper, to describe the main points of one of the most recent syndromes found in Finland.

Towards the end of 1963 the Finnish oculist Forsius and the population geneticist Eriksson asked my opinion as to whether a syndrome found by them among inhabitants of the Aland Islands in the Baltic Sea represented a new type of fundus albinism. My impression was that the clinical and functional disorders were mainly due to foveal hypoplasia; I had never seen a case of fundus albinism as described by Vogt, and the scarce literature on the subject was hardly convincing, if only because the range of pigmentation towards the periphery of the fundus is not too well established. They agreed with me about the foveal hypoplasia, but in their publication (Forsius and Eriksson, 1964), they put forward the diagnosis of fundus albinism. When I was invited to read a paper before the Finnish Ophthalmological Society in January 1966, I chose as my subject 'Albinism and Leukism in General and in the Human Eye' and I had the opportunity of seeing 14 members of the kindred in question (Fig. 1), some affected and some unaffected.

\section{Ophthalmological Appearances in Affected Males}

Seeing this family confirmed me in my diagnosis of a primary foveal hypoplasia similar to that present in ocular albinism, in the different forms of generalized albinism, in congenital achromatopsia, 


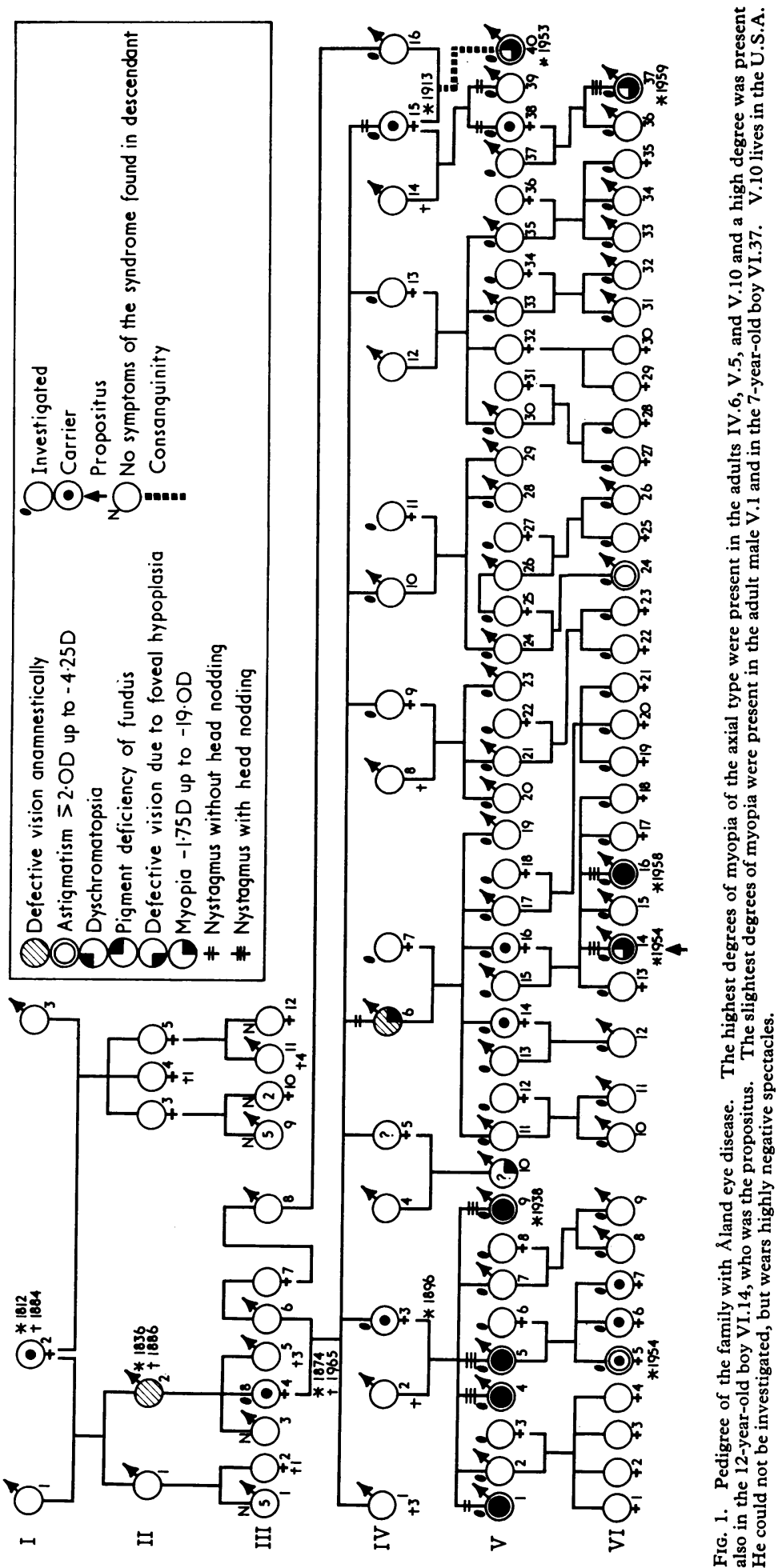


in aniridia, and in high-grade hyperopia with and without microphthalmia. In my view we were dealing not with fundus albinism but with multiple localized areas of deficiency in pigmentation. These areas were unequal in size and in the degree of pigment deficiency, and were mainly situated around the disc and the fovea (Fig. 2 and 3). Towards the periphery of the fundus the appearances were nonuniform, conforming to normally pigmented types, with their lighter or darker patches, seen in normal iris and hair colour. The fundus photographs which my colleagues kindly sent me made it easy to distinguish the appearances in unaffected males, carrier females, and affected males. The affected males did not always present only a hypoplasia or local aplasia of the fovea. Some of the younger boys showed a combination of hypoplasia with dysplasia; this dysplasia could be recognized by the presence of a clearly prominent rim along a part of the fovea, while the foveolae were nearly always absent or deformed, and the macular yellow, reflexes, and some capillaries were all missing or very irregular. The failure of development of a normal fovea usually contributes to bad vision and some optokinetical nystagmus. Scattered chalkwhite 'exudates' were frequent. One of the main symptoms was axial myopia; this was present in early youth and progressed to reach a high degree (up to $20 \mathrm{D}$ ) but remained always benign. Regular astigmatism up to $5 \mathrm{D}$ was also a general symptom.

\section{Other Aspects}

Appearances in female carriers. Females who, as daughters or mothers of affected male patients, were undoubted carriers did not show any characteristic symptom of the syndrome.

Nystagmus. In the right branch of the pedigree IV.15 was a sister of IV.6, an affected male who died at the age of 44 . He had two carrier daughters, V.14 and V.16 and was by V.16 the grandfather of two affected grandsons, VI.14 and VI.16. The above IV.15 is also a sister of IV.3, who is still living and is the mother of four affected sons, V.1, V.4, V.5, and V.9. V.5 has 3 daughters, who must be carriers like the women V.14 and V.16. The nystagmus found in the affected males was originally interpreted as optokinetic in origin. These patients have since been extensively investigated by $\mathrm{Dr}$. Lumio of Helsinki and Dr. van Vliet of Rotterdam, and the findings will be reported fully at a later stage.

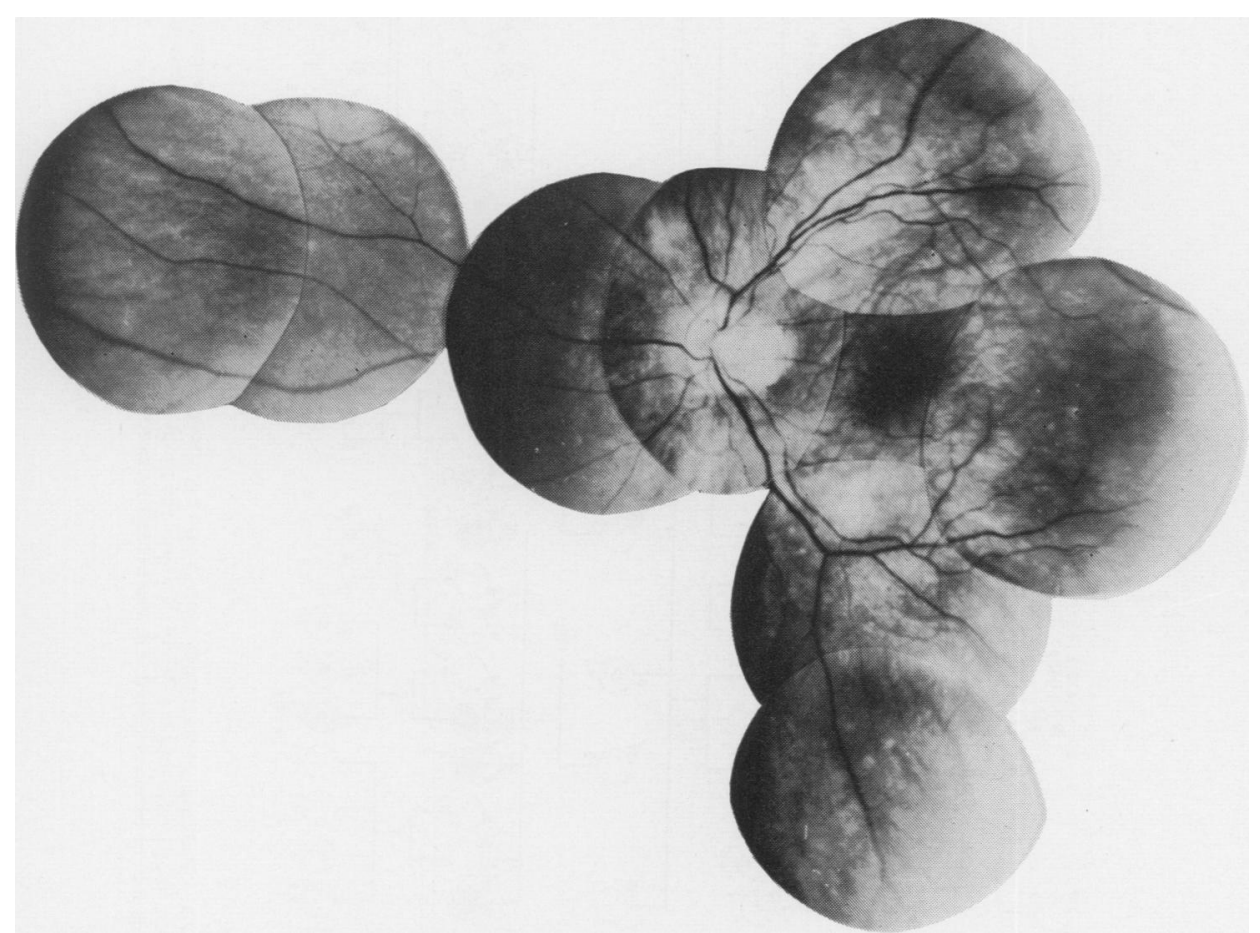

FIG. 2. Irregularly pigmented areas in V.5 (left eye). 


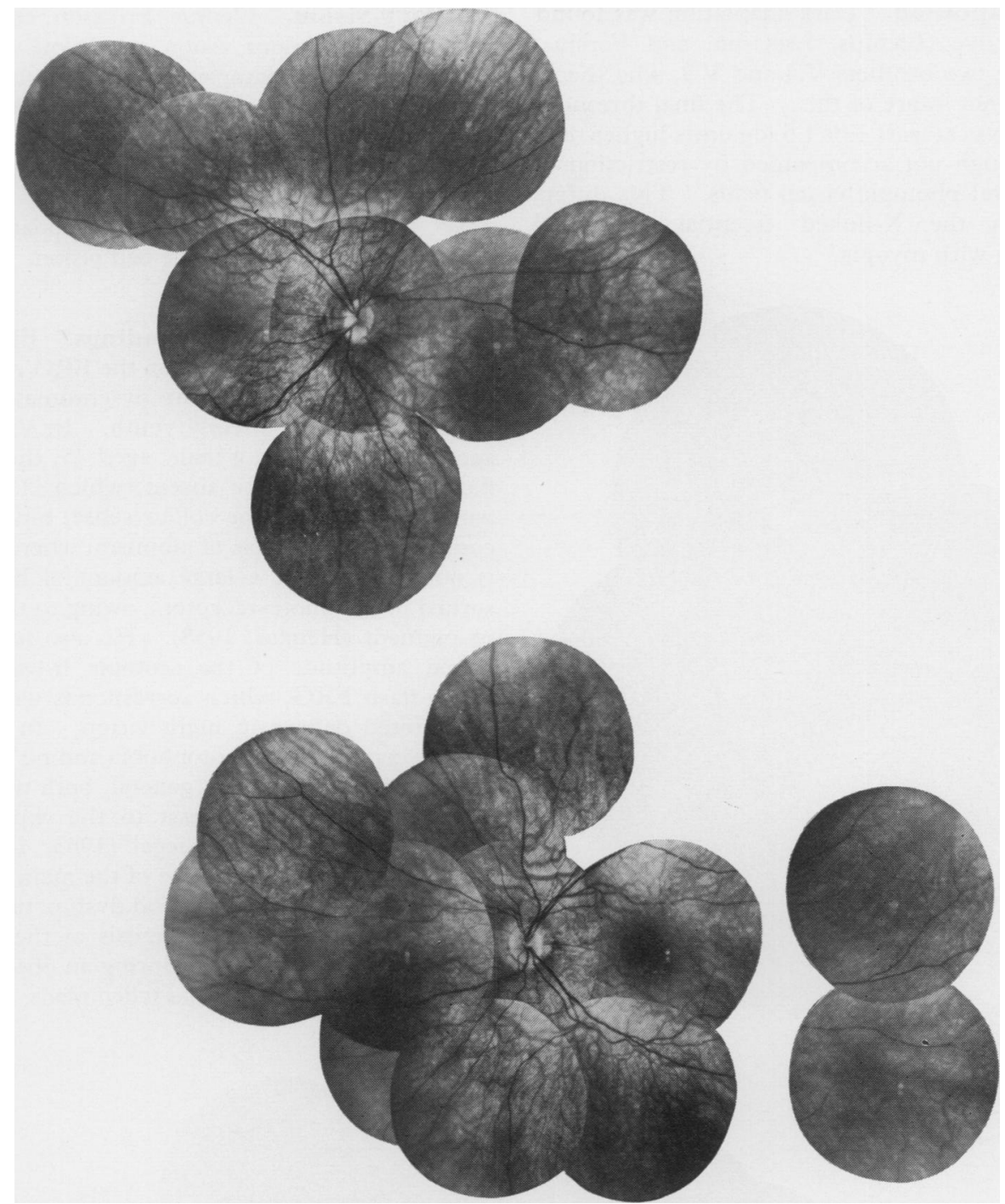

FIG. 3. Right and left eye of the young boy VI.37 (at the age of 5). The areas poor in pigment were small. The round separate photographs present peripheral areas. Dyschromatopsia was nearly absent.

Here it is only necessary to point out that a very slight irregular nystagmus has been found in the right branch of the pedigree in the mother IV.15 and the daughter V.38. Soon after, it seemed also to be present in the son V.39, but it was absent in the son of her second marriage, V.40 (he has other defects but not nystagmus). At first, we assumed that one of the three known types of hereditary extra-ocular nystagmus* had entered the family from another source, but from the investigations of

* The irregularly-dominant X-linked type occasionally decreases or disappears later on, especially in females.
Dr. van Vliet on the Alland Islands it seems more probable that in this branch a fourth extraocular type has entered in the form of latent nystagmus. This was also present in the half-brother, V.39, who moreover suffered from alexia. Van Vliet localizes its origin probably in brain centres (the pontine and mesencephalic tegmentum). Latent nystagmus is also hereditary, but it is not yet known with certainty in what way. According to Crone (1952), latent nystagmus is often correlated with alternating hyperphoria. This was not present in this family. 
Dark adaptation. Dark adaptation was found to be defective (Elenius, Eriksson, and Forsius, 1968 ) in the two brothers V.4 and V.9, who themselves were not aware of this. The final threshold in the dark was at least 1 or $1.5 \log$ units higher than normal, though not accompanied by restriction of the peripheral photopic visual fields. This differs much from the $\mathrm{X}$-linked essential congenital hemeralopia with myopia.

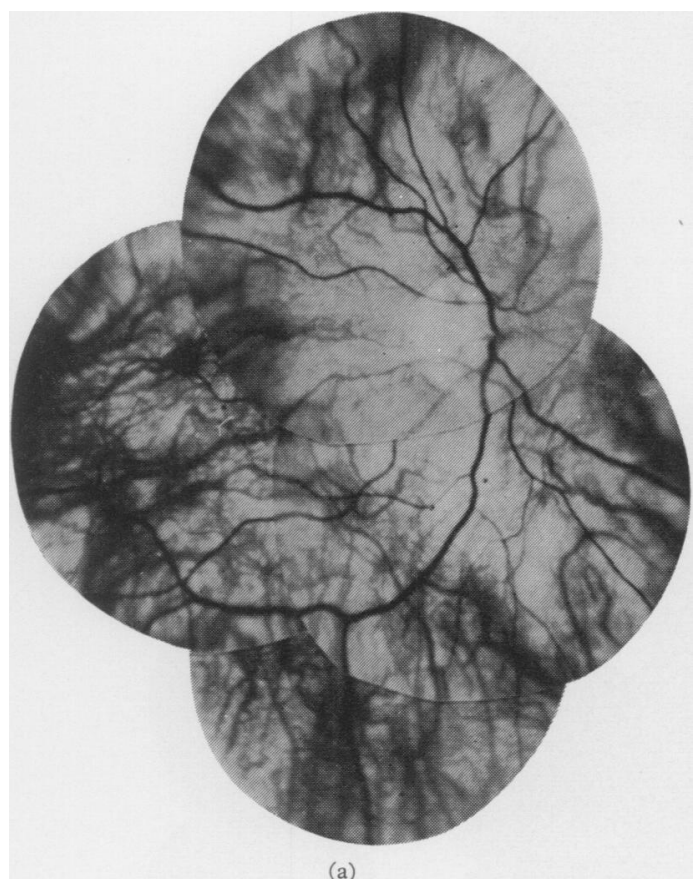

Colour vision. Elenius, Eriksson, and Forsius also examined colour vision on various occasions. A slight dyschromatopsia has been observed in affected members (mistakes in the 100-hue test, anomaloscopic widening, and displacement of the normal Rayleigh match to the protanomalous side), but this did not represent one of the congenital types. It must, therefore, be a secondary trait, or connected originally with the bad vision.

Electroretinographic findings. Elenius observed the following results on the ERG recordings. In VI.37 (Fig. 3), a slight dyschromatopsia was minimally present in early youth. In V.4, a male, aged 40 , and in V.1, a male, aged 45 , the photopic flicker potentials were absent, which is consistent with the defects of the colour sense, but would be contrary to a diagnosis of albinism, where the ERG is normal, because a large amount of light is absorbed in the photo-receptors, owing to the absence of pigment (Henkes, 1958). He also found a reduced amplitude of the scotopic b-wave of the single flash ERG, which corresponds with the demonstrated defects in night vision. In V.4 there was no complaint of photophobia and no preference of dim illumination. In general, both were absent in the patients, in contrast to the experience of Goodman, Ripps, and Siegel (1963, 1965), who found photophobia to be one of the main symptoms in several cases of cone and rod dysfunction.

Elenius's pessimistic prognosis of the condition conflicts with the fact that during an observation of 6 years, no deterioration has taken place.

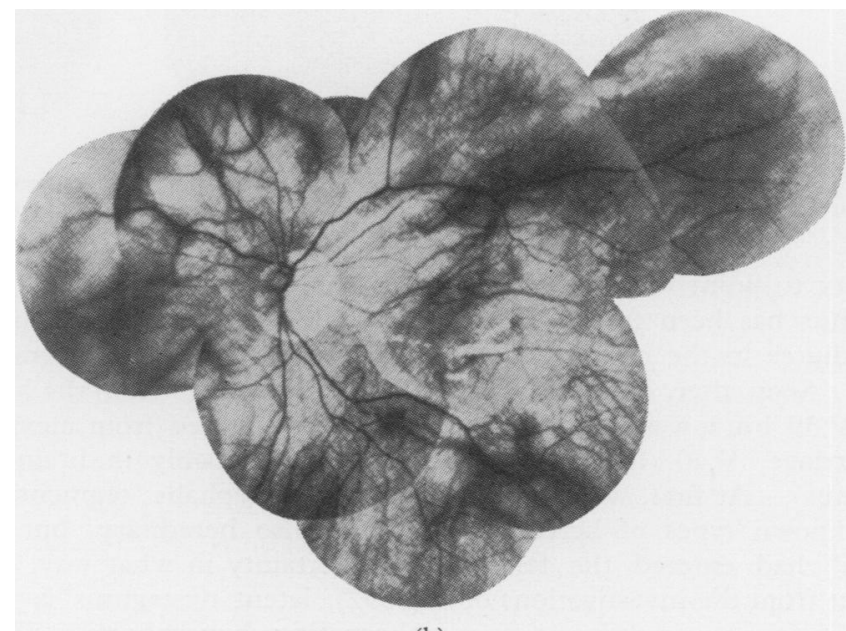

(b)

Fig. 4. (a) Right eye of V.9; (b) Left eye of V.9. Ruptures of the membrane of Bruch. 
Further considerations on four affected brothers in generation V. (1) Myopia: it is of interest that the degree of myopia in V.1 is the lowest seen in these patients, and was not due to counteraction of a hyperopic gene from the father's side. (2) Appearances recalling ruptures in Bruch's membrane: these were seen in the left fundus of V.9 (Fig. 4).

It is possible that the observations on this family are to be explained not in relation to albinism but on the assumption that the anterior layer of the embryonic optic cup had a stronger growth tendency than the posterior one.

\section{REFERENCES}

Crone, R. A. (1952). Alternerende Hyperphorie. Thesis, Amsterdam.

Elenius, V., Eriksson, A., and Forsius, H. (1968). ERG in a case of $\mathrm{X}$-chromosomal pigment deficiency of fundus, in combination with myopia, dyschromatopsia and defective dark-adaptation. The Clinical Value of Electroretinography. TSCERG Symposium, Ghent, 1966, pp. 369-377. Karger, Basel and New York.

Forsius, H., and Eriksson, A. W. (1964). Ein neues Augensyndrom mit X-chromosomaler Transmission. Eine Sippe mit Fundusalbinismus, Foveahypoplasie, Nystagmus, Myopie, Astigmatismus und Dyschromatopsie. Klinische Monatsblätter für Augenheilkunde, 144, 447-457.

Goodman, G., Ripps, H., and Siegel, I. M. (1963). Cone dysfunction syndromes. Archives of Ophthalmology, 70, 214-231.

$\longrightarrow$, and (1965). Sex-linked ocular disorders: trait expressivity in males and carrier females. Archives of Ophthalmology, 73, 387-398.

Henkes, H. E. (1958). Differentiation and evaluation of rod and cone system responses in the human electroretinogram. Ophthalmologica, 135, 138-146. 